\title{
Melhores práticas na modernização do Estado*
}

\section{A avaliação das melhores práticas: o projeto}

O presente texto é um relatório preliminar de atividades de um projeto de pesquisa ainda inacabado sobre os principais progressos da modernização dos governos centrais em diferentes países ocidentais que passaram ou estão passando por processos de reforma. Ao contrário de outros esforços de avaliação, este documento não tenta identificar trajetórias de modernização de diferentes países e seus efeitos, nem mesmo estabelecer categorias ou tipologias de países. Ele tampouco tenta reconstruir o processo político da modernização, identificando e explicando aspectos como: a formação da agenda; os fatores indutores de mudanças; diversos conceitos e sua racionalidade ou base ideológica; as estratégias de implementação; os efeitos do projeto sobre o desempenho administrativo e seus resultados. Finalmente, o interesse primordial deste documento não é comparar os resultados de países distintos, os conceitos da reforma e/ou estratégias de modernização, atribuindo pontuação a cada iniciativa e elegendo vencedores e perdedores. Ao contrário, o projeto visa identificar aquelas mudanças que parecem estar funcionando. Observamos e tentamos identificar novas práticas que tenham evoluído de modo similar em diferentes países com tradições administrativas, com culturas e caminhos de reforma visivelmente distintos, e tentamos entender e explicar tais mudanças. Estamos bem conscientes de que os contextos são bastante diferentes, de que é grande a diferença entre "fazer" e "agir', e que ainda há muito mais variáveis explicativas e independentes do que características a serem explicadas,
Werner Jann é presidente do European Group of Public

Administration (EGPA) e professor de ciência política, administração e organização na Universidade de Potsdam,

Alemanha.

Christoph Reichard é $\mathrm{PhD}$ em Economia e Administração Pública pela Universidade de Freiburg e professor de Gestão Pública na Universidade de Potsdam,

Alemanha.

Contatos: jann@ rz.uni-potsdam.de puma@ rz.uni-potsdam.de Artigo publicado no International Journal of Political Studies $n^{\circ} 3$ de setembro 2001 . Traduzido por Maria Christiana Ervilha 
mas ainda assim estamos convencidos de que é possível - e necessário — aprender com as experiências de outros países.

As origens do projeto original remontam aos debates profissionais e políticos a respeito da modernização do setor público na Alemanha nos anos 90. Existe um nível considerável de acordo entre os especialistas sobre o fato de a República Federal não estar na "vanguarda" da modernização do setor público (ver, por exemplo, o estudo comparativo de Pollit e Bouckaert, 2000): as reformas administrativas inspiradas pelo denominado modelo anglo-saxão da Nova Gestão Pública, ou New Public Management (NPM) começaram tarde na Alemanha, não antes do início dos anos 90, a maioria no nível local. Até então, houve algumas iniciativas relevantes em certos municípios, embora o impacto de longo prazo destas iniciativas ainda seja confuso e incerto (Jann, 1997; Reichard, 1997). Alguns Länder federais seguiram a liderança local e começaram a introduzir algumas reformas na gestão pública, embora em escala muito menor, ao passo que a esfera federal ignorou os desafios gerenciais e reformistas até a década de 90 . Segundo alguns, isso se deu graças a boas e compreensíveis razões, visto que o governo federal estava preocupado com a unificação alemã e com a transferência da administração federal de Bonn para Berlim. Outros discordam, afirmando que o governo deveria ter usado esta "janela de oportunidade" única para promover uma reforma governamental mais radical, não somente para introduzir um certo espírito gerencial no governo federal, mas também e principalmente para implementar algumas das reformas há tanto devidas, presentes na agenda política, no mínimo, desde os anos 70 (por exemplo, a modernização do arcaico sistema de gestão de recursos humanos e financeiros e das estruturas tradicionais dos ministérios federais). Mas tudo isso só ocorreu na metade dos anos 90, quase no fim da era conservadora-liberal de Kohl, quando uma visão um tanto desfocada de um "Estado enxuto" (Schlanker Staat) foi desenvolvida por uma comissão de especialistas blue-ribbon (representantes de alto nível do meio acadêmico). Entretanto, a implementação das inúmeras propostas de reforma não se deu de forma sistemática, nem contou, digamos assim, com a dedicação de que necessitava (Jann e Wewer, 1998; König e Füchtner, 2000).

Quando, em setembro de 1998, o governo conservador-liberal do Chanceler Helmut Kohl foi sucedido pelo governo da coalizão "vermelha e verde", chefiado pelo social-democrata Gerhard Schröder, muitos pensaram, e até esperaram, que um novo espírito, um movimento em direção à reforma, fosse ganhar força. Modernizadores, a maioria à esquerda do espectro político e, em geral, a favor de um governo forte e democrático, viram a chance de fortalecer e, em última instância, reconstruir o serviço público por meio de reformas. A visão anterior e conservadora-liberal do "Estado enxuto" foi substituída pela nova Leitbild do "Estado ativo" 
(“activating state”). Assim, a mudança governamental parecia oferecer uma oportunidade única de introduzir abordagens de "nova" governança e estruturas gerenciais na esfera central (Bund) e, até certo ponto, nos níveis estaduais (Länder). Nesse contexto, emergiu em nosso grupo a idéia de realizar um projeto de pesquisa para coletar e analisar os progressos inovadores em países com diferentes estilos de reforma, tentando identificar as "melhores práticas" e alimentar com as conclusões a discussão alemã — fornecendo a tempo alguns insumos relevantes aos processos políticos e às "coalizões de advocacy" da atualidade.

A idéia básica, proposta por Frieder Naschold, era identificar grandes inovações no campo da reforma de governos centrais, com a colaboração de um grupo de conhecidos especialistas internacionais em administração e gestão pública, e transferi-las para o debate recentemente retomado na Alemanha. Todo esse empreendimento foi financiado por uma bolsa da Hans-Boeckler-Stiftung, uma fundação de sindicatos alemães. Foram selecionados sete países cujas experiências pareciam particularmente interessantes para a Alemanha, e, além dos dois autores deste artigo, Frieder Naschold convidou uma equipe de especialistas internacionais da Dinamarca (Carsten Greve e Lotte Jensen), Estados Unidos (Don Kettl), Países Baixos (Walter Kickert), Nova Zelândia (June Pallot), Reino Unido (Fred Ridley e Morton Davies), Suécia (Stig Montin) e Suíça (Kuno Schedler). Cada especialista tinha a missão de selecionar, descrever e analisar as inovações mais bem-sucedidas de seu país, com base em um projeto de pesquisa comum.

Os relatórios de cada país deveriam enfatizar principalmente a implementação de práticas e processos reais e o impacto de tais inovações. Os relatórios deveriam basear-se, sempre que possível, em avaliações existentes, realizadas tanto pelos governos quanto por agências avaliadoras, cientistas ou instituições independentes. Assim, a essência dos relatórios deveria focalizar experiências e práticas inovadoras, e não o desenvolvimento e a análise conceitual — que parecem ainda muito comuns nos relatórios de "Estado da arte" da modernização do setor público, principalmente no campo da NPM. Também ficou definido que seria de grande valia se os relatórios dos países se referissem a áreas políticas ou projetos claramente definidos, e não a estratégias e programas de modernização em geral.

Os relatórios dos distintos países foram detalhadamente discutidos em duas conferências em Berlim, e um curto resumo das principais conclusões foi publicado na Alemanha (Naschold, Jann e Reichard, 1999). Infelizmente e inesperadamente, Frieder Naschold faleceu no meio do projeto, e a pesquisa ficou temporariamente paralisada. No momento, o relatório final está sendo preparado e deverá ser publicado em breve. A seguir, apresentamos uma rápida descrição de algumas das conclusões que nos parecem mais interessantes. 
Enquanto o relatório de cada país procurava identificar "as melhores práticas", buscando-as nos estudos e avaliações disponíveis, documentos oficiais, declarações governamentais e todo tipo de informação acessível — e finalmente, mas igualmente importante, na experiência e o julgamento crítico e bem-informado dos próprios relatores, uma das principais tarefas do projeto era identificar os traços e experiências comuns entre os diferentes países. Está claro que experiências, estratégias, sucessos e fracassos diferem profundamente, até mesmo dentro da amostra relativamente homogênea de "países reformistas", mas havia ainda algumas mudanças importantes em comum, que tiveram impacto em alguns dos países selecionados. A seguir, iremos nos concentrar em três das principais conclusões: na nova lógica de atuação no nível do governo central (criação de agências executivas e de contratos de gestão), nas inovações no campo da política de recursos humanos ("normalização" dos sistemas de pessoal) e na gestão das finanças públicas (orçamento e finanças). Concluiremos com algumas observações sobre estratégias de implementação (políticas administrativas) e a respeito de algumas experiências desse tipo de esforço de cooperação internacional para a realização de pesquisas.

\section{Agências e contratos}

Um dos resultados óbvios a serem extraídos da amostra de países é que praticamente todos os governos adotaram e implementaram alguns dos conhecidos conceitos e instrumentos da NPM para a modernização inter e intra-organizacional dos ministérios e outras instituições governamentais - o que segue, de certa forma, a lógica da descentralização, do gerenciamento de contratos centrado no desempenho e no monitoramento de resultados. Mas a conclusão mais interessante é que tais elementos, ao menos na esfera do governo central, parecem ter sido implementados com mais sucesso na relação entre os ministérios e as instituições a eles subordinadas - estabelecendo uma "nova lógica de atuação no governo central, que tenta deixar para trás o clássico controle político/burocrático e a função de supervisão e avançar em direção a novas formas de agencificação e contratualização.

Essencialmente, em todos os países pesquisados, observamos a mesma tendência geral: há uma crescente devolução das tarefas dos ministérios e departamentos centrais para agências e organizações, públicas, privadas ou híbridas, todas elas mais ou menos independentes. Em praticamente todos os países isso demandou alguma forma de descentralização vertical rumo aos governos locais e regionais, ou outros tipos de descentralização política e administrativa. Mas como os sistemas de governo local e os federalismos diferem entre si em uma escala ainda 
maior do que em outros contextos administrativos, concentramo-nos na devolução horizontal de tarefas (ver Figura 1; para uma breve descrição das novas formas de coordenação vertical e gestão em múltiplos níveis, ver Naschold, Jann e Reichard, 1999). Existe, obviamente, financiamento externo e contratação de serviços e tarefas específicas, privatização (conferindo responsabilidades e tarefas ao setor privado) e corporatização (com a criação de organizações híbridas, pertencentes ao menos parcialmente ao público).

\section{Figura 1: Ministros e a devolução horizontal das tarefas}

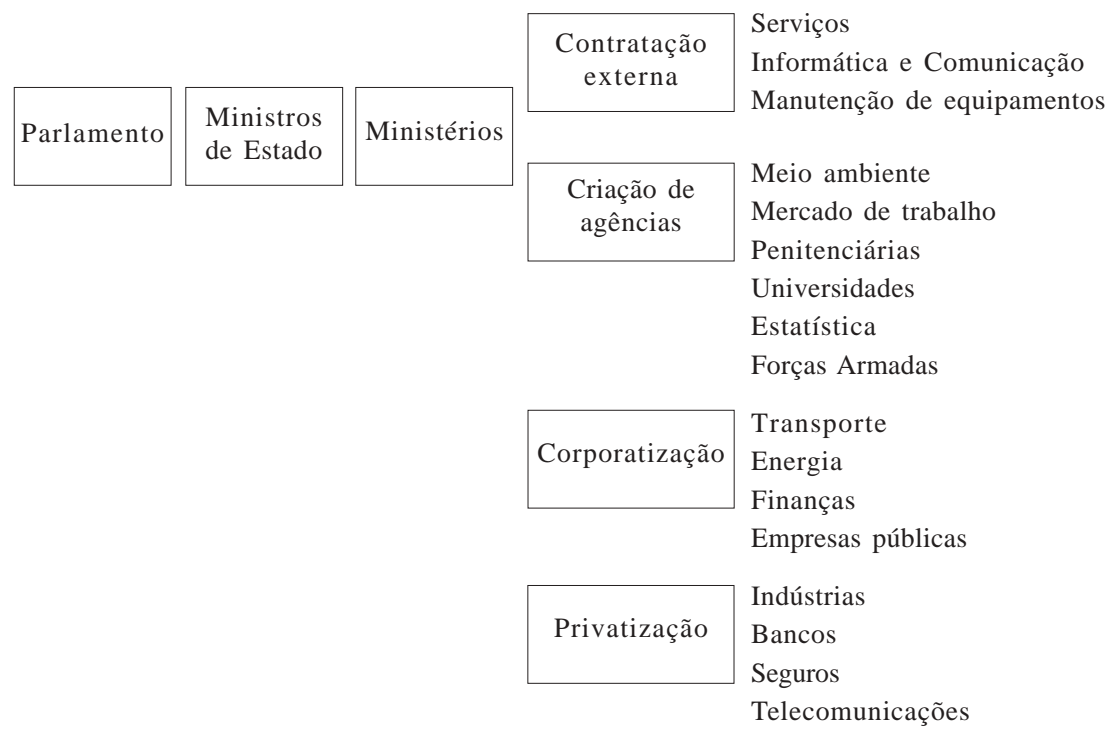

Mas enquanto essas tendências clássicas são bem conhecidas, e não modificam, na verdade, os arranjos organizacionais prevalecentes (embora elas tenham, certamente, um certo efeito no tamanho do setor público), os processos de criação de agências parecem introduzir novos elementos de orientação e controle, particularmente por meio do uso disseminado de contratos e preparação de relatórios, combinados com novas formas e maior liberdade dos sistemas de orçamento e pessoal, em um nível mais baixo. Assim, é a nova relação entre algumas agências reguladas por contratos e seus departamentos de origem que chama a atenção, e não o estabelecimento em si de novas agências (a exemplo da iniciativa next steps, ou próximos passos, na Grã-Bretanha), visto que alguns países possuem agências independentes há muito tempo, e visto que, a exemplo do que aconteceu na Alemanha - a maioria das tarefas que foram conferidas às agências na Grã-Bretanha nunca foram de responsabilidade dos Ministérios (Jann e Döhler, 2001). Os relatórios dos países demonstram uma grande variedade dessas novas relações em todos 
os países investigados (não só os "suspeitos de sempre" — Grã-Bretanha e Escandinávia — mas também os Países Baixos, Suíça e Estados Unidos), em todos os tipos de ministérios e setores políticos, da educação ao mercado de trabalho, das penitenciárias às Forças Armadas.

Os objetivos declarados desses novos arranjos institucionais são, de vários modos, as conhecidas bases doutrinárias da $N P M$, isto é, mais flexibilidade, transparência de custos e desempenho, aumento de qualidade, produtividade, eficiência e efetividade - também no nível central do governo, entre os ministérios e o resto da administração pública. Outros objetivos, mais recentes e mais difíceis de alcançar, são também mencionados, em particular aqueles que limitam a atual independência, quase "autárquica", das organizações governamentais, facilitando a formulação e implementação de prioridades novas e em constante mudança.

As estratégias gerais para atingir mais flexibilidade, transparência e orientação por metas na relação entre diferentes organismos e níveis governamentais são bastante conhecidas. No que diz respeito às finanças, há uma evolução do orçamento rígido e detalhado de autoridades subordinadas para orçamentos mais abrangentes e adaptáveis. Espera-se que a gestão de recursos humanos abandone os sistemas clássicos e unificados de pagamento, carreira e promoção, por soluções mais individualizadas e especializadas para cada tipo de setor, agência e pessoal. Finalmente, o objetivo primordial é substituir os mecanismos clássicos da burocracia, voltados para o cumprimento de regras e altamente hierarquizados, por redes e relações interorganizacionais que demonstrem flexibilidade, orientação por resultados e capacidade de aprender.

$\mathrm{O}$ instrumento mais importante e inovador para se alcançar metas tão intangíveis é, de longe, o uso de contratos entre ministérios e suas agências subordinadas, particularidade encontrada em todos os casos estudados. Há ainda uma convergência considerável na forma e nas funções desses contratos. O contrato típico é um instrumento escrito, geralmente assinado pelo ministro e pelo dirigente da agência. Não se trata de um contrato formal, isto é, ele não apresenta dispositivos legais, mas sim contém informações e acordos específicos sobre metas e resultados a serem alcançados, por exemplo sobre a qualidade dos serviços, tempo e recursos necessários para a obtenção de determinados produtos, o desenvolvimento e a mensuração da produtividade, a avaliação da "satisfação" do cliente e até mesmo a avaliação dos produtos (outputs) e resultados (outcomes) das agências. Os contratos podem incluir acordos sobre prioridades e "posterioridades", um compromisso acerca das condições sob as quais os resultados devem ser alcançados (o arcabouço legal, por exemplo) e especialmente a respeito dos recursos (financeiros, humanos e outros) disponíveis. Finalmente, os contratos explicitam responsabilidades mútuas e condições para seu término ou modificações. Em geral, os contratos 
têm duração de três ou quatro anos e, em troca de assegurar determinados

resultados e conquistas, dão às agências executivas considerável liberdade no uso de seus recursos. As agências ficam assim livres das restrições típicas quanto ao uso dos recursos financeiros e humanos, e também no que se refere à estrutura organizacional e ao uso de instrumentos gerenciais.

Outro importante instrumento utilizado em associação com o modelo contratual são as novas formas de prestação de contas (reporting). Em praticamente todos os países, exigências específicas relativas aos relatórios anuais foram introduzidas juntamente com os contratos. Dessa forma, as agências passam a preparar relatórios seguindo a linha da prestação de contas empresarial, encontrada no setor privado, tentando conter informação melhor e mais abrangente, necessária para se julgar os progressos alcançados pelas organizações públicas. O objetivo dessas novas exigências de prestação de contas é fornecer a todos os stakeholders, internos (lideranças, ministérios) e externos (parlamento, empresas de auditoria, cidadãos e o público em geral) um quadro mais amplo e confiável dos custos e benefícios das agências públicas. A forma e o conteúdo desses relatórios são, por vezes, determinados por longas regulamentações governamentais. Em geral, os relatórios devem conter informação do ano anterior a respeito de atividades, finanças, resultados, mas podem também incluir exigências mais específicas sobre temas como meio ambiente, gênero etc. Em alguns países (principalmente os escandinavos), os relatórios são parte integrante do processo de preparação do orçamento anual, e seus documentos estão disponibilizados via Internet; em outros, os relatórios chegam a ser avaliados pelo órgão nacional de auditoria, e recebem menção pela qualidade, variando de AA a CC.

A questão principal, é claro, ainda persiste - quais são, se houver, os efeitos e resultados globais desses novos modelos contratuais? Aqui, novamente, as diferentes avaliações e os vários sumários das nossas pesquisas nacionais mostram um panorama surpreendentemente similar. Apesar dos problemas conceituais e das dificuldades na implementação (ver a seguir), o cenário geral é encorajador. Os estudos disponíveis mostram que o modelo contratual sustenta e fortalece a efetividade e os níveis adequados de serviço e qualidade das agências governamentais. Além disso, estudos comparando "novas" agências regidas por contratos com as "antigas" instituições, com forte controle hierárquico, fornecem evidências quantitativas de que as agências mostram mais produtividade e uma orientação por objetivos muito mais clara. As agências regidas por contratos reforçam_outros elementos da nova gestão pública (por exemplo consciência dos custos, gestão de pessoal etc.) e, acima de tudo, ajudam a criar um diálogo amplo e estruturado entre departamentos e agências. No fim das contas, elas tornam mais fácil a avaliação do desempenho (e a identificação de fracassos) e fortalecem a transparência, ao menos para aqueles interessados nesse tipo de informação. 
Em quase todos os nossos países, uma "mudança cultural" significativa é citada como um dos mais importantes resultados. As atitudes e o comportamento dos funcionários têm se tornado mais voltados ao desempenho e à efetividade, e certamente mais gerencial (a abominável postura 'can-do' — “eu posso, eu faço") mas também mais autoconfiante. As agências acabaram tornando-se mais e mais atraentes para funcionários jovens, ambiciosos e bem-formados dos ministérios tradicionais, mesmo dos departamentos financeiros — o que é, seguramente, um bom indicador de sucesso.

É impressionante o fato de que em quase em todos os países (exceto, obviamente, Nova Zelândia e Reino Unido), as principais razões para o estabelecimento de agências reguladas por contratos não sejam as tão conhecidas doutrinas NPM de "principal- agente" e "cliente-fornecedor". Quando isso foi revelado de maneira explícita — e, de certa forma, crítica — em um relatório da OCDE-PUMA, a resposta dada pelo ministério de finanças dinamarquês foi um tanto interessante: os dinamarqueses afirmam que os contratos eram vistos inicialmente como um instrumento particularmente flexível para proporcionar ajuste e aprendizado organizacional, e não para controlar e restringir tais processos. O objetivo geral é um diálogo mais bem-estruturado e informado sobre as prioridades e "posterioridades" políticas e financeiras. Postos assim, como no caso dinamarquês, os contratos são usados em uma versão "soft", indicando uma "governança por contato", e não uma "governança por contrato".

O mesmo pode ser dito acerca do caso sueco. Também, nesse caso, os conceitos excessivamente racionalistas de orientação e controle são vistos com algum ceticismo, talvez por causa da avaliação sistemática da versão sueca do PPBS nos anos 60 e 70. Ao contrário, lá se afirma que a característica mais importante é o equilíbrio entre as demandas e os interesses, que podem ser diferentes e contraditórios. Uma abordagem mais ad hoc e flexível é, portanto, considerada aceitável. Os contratos são utilizados para superar algumas das patologias do controle burocrático, sempre por meio do estabelecimento de um fluxo contínuo de informações, debates e consultas a respeito dos objetivos, instrumentos, desempenho e resultados das políticas governamentais. Dessa forma, as relações entre os ministérios e as agências são mais caracterizadas pela confiança do que pelo comando e controle. A supervisão e a direção verticais, de cima para baixo, são menos importantes do que a coordenação dos recursos, atividades e metas. Novamente, nas palavras do estudo de caso sueco, os "limites baseados na confiança", em vez dos "limites regulamentais" ou "limites contratuais" caracterizam de forma mais apropriada o desenvolvimento das relações entre as várias instituições do estado de bemestar sueco. 
Apesar do caráter geralmente positivo dessas avaliações, existem, certamente, sérios problemas e conflitos por detrás da nova lógica orientadora das agências regidas por contratos. Com mais freqüência nas avaliações independentes disponíveis, mas também em alguns relatórios de auditoria e de ministérios de finanças, vários problemas recorrentes foram mencionados:

- existência de contratos muito simples, com objetivos pouco ambiciosos ou exigentes;

- ainda assim, nem todos os objetivos declarados são atingidos (e com freqüência isso sequer é percebido pelos ministérios responsáveis);

- atividades importantes das agências não constam dos contratos;

- os objetivos são, muitas vezes, pouco específicos (excessivamente detalhados, o que leva a um deslocamento da meta ou a outras respostas tradicionalmente burocráticas);

- os objetivos são formulados de forma muito vaga, o que torna difícil, por vezes impossível, verificar seu cumprimento; e

- muitas vezes não há sanções para metas e promessas nãocumpridas.

Além dessas falhas - de caráter geral e em princípio bem conhecidas — da gestão contratual, foram apontados problemas específicos. $\mathrm{Na}$ maioria dos casos e dos países, fica claro que os contratos são mais influenciados pelas agências do que por seus departamentos de origem. Políticos, e também ministros, são raramente muito envolvidos nas negociações dos contratos, e freqüentemente o interesse dos atores políticos (parlamentares, partidos etc.) e do público em geral nesses acordos é bastante pequeno, para dizer o mínimo.

Em um nível mais técnico, os relatórios são criticados por serem muito longos, extensos, excessivamente descritivos e pouco analíticos. Há uma tendência a dar um tom burocrático e técnico ao processo, que passa a se concentrar em cifras pseudo-exatas, modelos e requerimentos formais, e não na sua relevância prática. Nos casos em que há dados disponíveis, eles são utilizados, mas não necessariamente são úteis e essenciais. Os problemas de assimetria de informação podem se tornar mais evidentes e mais transparentes no caso dos modelos contratuais, mas não chegam a desaparecer.

Por fim, é evidente que nem todas as organizações estão satisfeitas com os contratos. Atores diferentes perseguem diferentes objetivos e agendas ao promovê-los e introduzi-los. Algumas agências temem perder autonomia, alguns ministérios temem perder o controle, e assim, ao final, os arranjos contratuais têm que lidar com distintas percepções de interesses - quem ganha e quem perde - e, portanto, com a consciência e a realidade do poder. 
Tendo em vista estes problemas, que são consideráveis, uma questão óbvia se apresenta - se podemos de fato identificar uma nova forma de governança na gestão por contratos, ou se o que observamos é algo distinto. A resposta, principalmente para os estudos de caso um tanto detalhados dos países escandinavos, parece sugerir que a gestão por contrato é raramente encontrada no Estado puro, tecnocrata, da literatura sobre gerenciamento, em uma forma excessivamente real, prática e ajustada. Existem poucos contratos "rígidos", com metas específicas e quantificáveis e sanções — positivas ou negativas — tangíveis, como prega a abordagem teórica. Mas há muitos processos contínuos, mais abertos e sistemáticos, de negociação e ajuste de objetivos, processos e desempenho, e de contínuo aprendizado mútuo. A gestão por contrato é vista cada vez menos como um jogo de soma-zero de autonomia e controle, e mais como um processo compartilhado de aprendizagem e ajuste.

\section{Normalização dos sistemas de pessoal}

O segundo resultado geral da nossa pesquisa diz respeito à importância e às mudanças significativas em todos os aspectos de gestão de pessoal, remuneração e recrutamento. Quase todos os países realizaram esforços consideráveis no campo da gestão dos recursos humanos, e têm, na sua maioria, renovado e reformado os sistemas do serviço público. Além disso, em grande medida, os governos parecem reconhecer que os esforços de reforma requerem a participação ativa e a efetiva motivação de seus servidores. Em quase todos os "países reformistas" podemos observar as seguintes inovações, que parecem particularmente interessantes e estimulantes:

- uma "normalização" generalizada do serviço público, isto é, a convergência dos regimes e condições trabalhistas dos setores público e privado, rumo a um sistema mais similar e unificado;

- a descentralização das competências de recursos humanos, das agências centrais para ministérios e agências locais;

- um recrutamento mais pluralista de diversas profissões para posições no serviço público, como por exemplo a constante admissão de economistas, cientistas políticos e administradores (públicos);

- introdução de conceitos de remuneração ligados ao desempenho e de contratos de trabalho por tempo determinado para altos burocratas;

- estabelecimento da carreira do "Serviço Executivo" para formar e remunerar os altos gerentes de forma adequada e inovadora; e

- novas formas de redução efetiva dos quadros dos servidores públicos. 
A integração dos sistemas de serviço público ao regime trabalhista geral do setor privado de um país (o que os holandeses chamam de "normalização") parece ser a inovação mais interessante e radical, especialmente para os Estados europeus de administração clássica como a França, Itália, Espanha e Alemanha. A vantagem dessa mudança de paradigma é percebida quando se dá a abertura do serviço público, quando ele se "desembaraça" de um sistema estatal centralizado, isolado e sem vínculos. Em seu cerne está a redução dos privilégios e diferenciações tradicionais, que não parecem mais funcionais. A normalização deve aumentar as oportunidades de rotação e intercâmbio de pessoal entre os setores público e privado, e pode contribuir para um trabalho mais dirigido ao desempenho e às condições de remuneração no setor público, promovendo assim a equalização, aprendizagem e competição entre os dois setores.

A normalização, entre outras coisas, significa que a maior parte dos servidores governamentais - a parte de um pequeno núcleo de servidores que ainda desfrutam de direitos específicos (como juízes, policiais, membros especiais do corpo governamental) - têm um contrato de trabalho "normal", e que suas relações de trabalho são reguladas pela lei trabalhista comum do respectivo Estado. Funcionários não gozam mais de contratos vitalícios, sistemas especiais de aposentadoria e outros privilégios tradicionais bastante conhecidos. Eles passam a ser, de certa forma, tratados como o resto da força de trabalho do seu país.

Outra conseqüência da normalização é a forma mais "normal" de recrutar e capacitar o pessoal para os postos nas organizações do serviço público. Ao passo que os sistemas administrativos clássicos recrutam e capacitam seus servidores de maneira específica e exclusiva, isolados do setor privado, o que torna a rotatividade entre os setores público e privado difícil, senão impossível, a maior parte dos Estados reformistas da nossa amostra buscam mais ou menos as mesmas profissões e qualificações que o setor privado. A ampla gama de profissões e a troca regular de funcionários entre os setores público e privado parecem ser uma importante pré-condição para uma "mudança cultural”, de valores burocráticos para outros mais profissionais, gerenciais e ligados ao desempenho.

O fortalecimento da orientação por desempenho na gestão de recursos humanos é outro tópico importante para os principais países reformistas. Muitos países tentam reestruturar o sistema de incentivos dos servidores públicos para avaliações mais justas e premiações pelo desempenho. De um lado, um amplo espectro de incentivos não-materiais é oferecido, entre eles claras responsabilidades e competências decisórias, tarefas que oferecem mais desafios, contatos mais satisfatórios entre grupos (ou equipes) e um comportamento que motiva a liderança. Por outro lado, todos os Estados estão experimentando novos esquemas de pagamento, mais orientados ao desempenho, ao menos para os servidores em cargos de liderança. 
Mais uma vez, nem sempre as avaliações são positivas. Muitos dos países relatam efeitos encorajadores da relação desempenho/pagamento, mas também há experiências críticas, principalmente em relação à avaliação do desempenho e à proibição de pagamento antecipado de bônus. Caso os critérios sejam pouco claros, os bônus muito pequenos ou disponíveis apenas para um pequeno número de funcionários, os sistemas de pagamento relacionados com o desempenho gerarão muito mais desmotivação do que motivação. Mesmo a descentralização da gestão, recrutamento e remuneração de pessoal apresenta suas falhas. Estudos de caso apontam para o abuso de gestores, principalmente nos casos em que as competências não tinham sido claramente definidas ou os gestores tinham sido pouco preparados para suas novas tarefas.

Com todas essas estratégias de reforma, um perigo plausível e potencial é o de que valores específicos e atitudes éticas, que eram — até certo ponto - comuns ao serviço público tradicional, percam-se e sejam substituídos por atitudes comuns, iguais às normais e costumeiras encontradas em qualquer emprego privado. O desaparecimento da ética do serviço público pode, no final, abrir oportunidades para o comportamento oportunista, e até mesmo para a corrupção. Há indicações de que, em alguns dos países pesquisados, esse seja um perigo bastante real.

\section{Contabilidade em tempo real (Accrual Acounting) e orçamentação por produto}

Por fim, os sistemas de gestão financeira, principalmente os relatórios contábeis, orçamentários e financeiros, foram identificados como instrumentos úteis e necessários para a modernização administrativa, e para que os governos possam ter a transparência necessária da sua situação financeira, dos recursos utilizados e dos ativos e obrigações existentes. Todos os países da nossa amostra realizaram esforços sérios para renovar seus sistemas e práticas de gestão financeira, e todos parecem estar em vias de convergir seus conceitos com as abordagens comerciais do setor privado. Dois campos de inovação têm particular relevância: a tendência à adoção de conceitos de contabilidade em tempo real baseada em recursos, e os recentes desenvolvimentos no campo da orçamentação por produto.

A maioria dos "Estados reformistas" introduziu recentemente, principalmente na década passada, conceitos de contabilidade em tempo real, isto é, um sistema contábil onde as transações financeiras são registradas no momento em que são "realizadas". Na prática, isso significa que o uso e consumo de recursos, como investimentos ou capital humano, são registrados durante todo o período de execução contábil — seja por depreciação, por 
cálculo dos encargos de capital ou pelo registro das provisões pensionistas.

Esse sistema contábil baseado em recursos é bem conhecido pelo setor privado, e seus princípios maiores foram transferidos - muitas vezes por meio de padrões nacionais de contabilidade como o Generally Accepted Accouting Principles - GAPP (Princípios Contábeis Geralmente Aceitos) - para o setor público. Em geral, esse sistema contém ao menos três componentes principais: uma declaração de fluxo de caixa (recibos e despesas de caixa), uma declaração de rendimentos (comparável às declarações de lucros e perdas no setor privado: um registro de receitas e despesas) e uma folha de balanço (que registra todos os ativos e obrigações, incluindo a infraestrutura pública e os ativos herdados, provisões de pensionistas e, em quase todos os casos, de eqüidade).

Esse tipo de sistema contábil, afirma-se, é muito mais informativo, no que concerne a todos os tipos de transações e ativos relevantes, do que o tradicional sistema contábil público, com base no fluxo de caixa. Ele é capaz de informar aos chefes de divisão ou seção o custo total de suas unidades e dos serviços produzidos, fornecendo assim dados relevantes para decisões voltadas para mais eficiência. Além do mais, ele promove a justiça intergeracional, visto que registra o consumo de recursos no período em que ele ocorreu. Isso parece ser especialmente relevante para dívidas de longo prazo ou pensões de servidores a serem pagas no futuro. De fato, tal sistema contábil fornece um quadro mais realista da situação econômica e financeira do governo como um todo, ou de uma determinada organização do setor público.

Alguns países do nosso estudo confiam inteiramente no sistema de contabilidade em tempo real, outros praticam ambos os conceitos de acréscimo e de caixa: contabilidade em tempo real para departamentos e agências governamentais, sistema de caixa para a contabilidade governamental como um todo. Alguns países chegam a aplicar os dois conceitos no nível governamental agregado. No geral, parece existir uma tendência clara: a comunidade profissional internacional está a um passo de concordar com os princípios contábeis comuns do setor público, com algumas particularidades no momento de avaliar os ativos ou calcular custos. Os International Public Sector Accounting Standards - IPSAS (Padrões Internacionais Contábeis para o Setor Público) da Federação Internacional de Contadores são um exemplo bem elaborado e praticamente concluído. Outra tendência interessante é a convergência dos sistemas contábil e orçamentário para uma base padronizada de acréscimo comum. Como se pode observar em vários dos nossos países, ambos os sistemas baseiamse em dados que mostram o consumo e a produção de recursos presentes e futuros.

Praticamente todos os países da nossa amostra experimentaram alguma forma de flexibilização da formulação e execução orçamentária, 
com estruturas de orçamento orientadas por produto. Em linhas gerais, essa não é, certamente, uma tendência nova. Várias nações realizaram, durante décadas, esforços contínuos para modificar seus conceitos orçamentários, do orçamento-insumo puro para as variações orçamentárias por produto. As mais conhecidas são as atividades do PPBS nos anos 60 e 70. Por diversas razões, na maioria das vezes em virtude do "exagero" tecnocrata e racionalista, esses primeiros esforços não alcançaram sucesso nem sustentabilidade. Porém, dentro do movimento geral da $N P M$ e seus fundamentos racionalistas, os governos redescobriram o desafio do orçamento-produto e elaboraram novos conceitos e aplicações para essa variação orçamentária. Os orçamentos de todos os Estados vêm se tornando mais e mais globalizados e com menos itens, comparando-se com o passado, e fica mais fácil transferir fundos entre seus itens. A tendência rumo ao "orçamento de um item só" permite maior flexibilidade para gestores financeiros e chefes de departamentos ou unidades menores de tomada de decisão durante o ano orçamentário.

Outro exemplo específico é o orçamento plurianual, introduzido particularmente na Suécia. Do ponto de vista da gestão financeira, parece altamente recomendável não confiar somente em orçamentos anuais, mas também tornar o crescimento financeiro de médio prazo mais transparente. Entretanto, esse tipo de orçamento requer um alto nível de disciplina daqueles que tomam as decisões políticas, para garantir o cumprimento dos itens plurianuais definidos. O segredo do caso sueco parece estar no fato de que o parlamento decide inicialmente o volume total e os níveis máximos de gasto ("landmarks") para cada orçamento ministerial, antes de chegar aos detalhes das dotações.

Em todos os Estados contidos no nosso estudo, encontramos oportunidades memoráveis de tornar a execução orçamentária mais flexível. A transferência de dotações entre itens diferentes dentro do mesmo grupo de produtos, em linhas gerais, não enfrenta mais restrições. Além disso, o carry over dos recursos financeiros para o ano orçamentário seguinte é, com algumas limitações, normalmente aceitável e possível. Alguns estudos sistemáticos (a maior parte realizada em países escandinavos) comprovam que a flexibilização da execução orçamentária pode levar a notáveis ganhos em termos de eficiência.

Estruturas orientadas por programas ou produtos podem ser encontradas no orçamento federal de alguns países. A tomada de decisão política se faz com base em dados mais ou menos genéricos sobre produtos e metas de impacto, as relativas dotações orçamentárias, e a informação sobre como tais metas devem ser atingidas (ver abaixo o trecho sobre o relatório de prestação de contas). A idéia central é de que o parlamento decida sobre um montante global de recursos a serem alocados em uma determinada agência ou conjunto de produtos, e que o departamento 
governamental (ministério ou agência) possa utilizar tais fundos dentro de uma determinada margem orçamentária e dentro de um conjunto de metas definidas, com alguma flexibilidade.

Novamente, as evidências disponíveis apontam para alguns problemas e falhas, sendo assim muito cedo para prever as chances definitivas de um orçamento mais flexível e orientado por produto. Por um lado, alguns fatores críticos, que causaram problemas no primeiro experimento orçamentário trinta anos atrás, são ainda válidos (fundamentalmente pressupostos ingênuos de natureza tecnocrata e racionalista relativos à vida política). Quanto mais flexível e orientado por produto o orçamento se torna, mais os instrumentos clássicos de controle e influência política tornam-se obsoletos. Além de tudo, o orçamento descentralizado e globalizado acentua os bem conhecidos problemas de fragmentação e coordenação. Por outro lado, desta vez o orçamento-produto está integrado a um conceito maior de gestão pública, e está mais afinado com sua característica de desembolso em bloco. Assim, as chances futuras de um orçamento-produto parecem ser mais realistas e positivas do que há 30 anos. Mas é claro que o orçamento globalizado só é factível se estiver combinado com um sistema de monitoramento e de elaboração de relatórios informativo.

O mesmo se aplica ao novo sistema de orçamento em tempo real. Ele oferece informações adicionais e mais realistas sobre o uso, a curto e longo prazo, dos recursos públicos, mas por outro lado diminui as oportunidades de controle que têm os ministérios de finanças, os ministérios de origem das agências e o parlamento. Por causa de escolhas viáveis e factíveis de avaliação de ativos, obrigações ou da futura execução de recursos, esse conceito permite mais e melhores oportunidades para manipular as contas públicas. Ele não é, dessa forma, tão claro e definitivo como um sistema contábil baseado em fluxo de caixa, mas é claramente mais ambicioso no que exige dos contadores e na sua operação diária.

\section{Lições aprendidas?}

Que lição, se houver alguma, pode ser aprendida desses exemplos de "melhores práticas"? Em primeiro lugar podemos aprender que certas inovações funcionam - ao menos em certos aspectos, e em determinadas circunstâncias. Sempre existirão problemas — de medida, de relações causais, de consequiências imprevistas - e as reformas nunca funcionam como se pretendia, mas elas têm certos efeitos, e alguns deles são positivos. É natural que sempre que ouvimos falar de conceitos, iniciativas e avaliações de reforma que só apresentam resultados positivos, vejamos tais histórias com o máximo ceticismo. Nenhum desenvolvimento 
organizacional modestamente complexo ocorrerá sem enfrentar o mais comum de todos os fenômenos sociais - processos e resultados imprevistos e até impensáveis. Ainda assim isso não significa que a mudança seja impossível ou que os produtos e resultados sejam aleatórios.

"Melhores práticas" são difíceis de se identificar e não podem ser entendidas ou explicadas sem um profundo entendimento do contexto. Mas alguns países estão retirando suas próprias lições, alguns até identificando "melhores práticas" quase-oficiais (como na Dinamarca), e deveria ser óbvio que outros países devessem ao menos considerar tais experiências. Ao tentar identificar e entender as "histórias de sucesso" e aprender com elas, mesmo que o sucesso seja modesto e contestado, podemos ganhar conhecimento "utilizável" (Cohen e Lindblom, 1979) sobre políticas institucionais, sua estrutura conceitual e seus prováveis efeitos. As evidências fundamentais e os pressupostos causais a respeito do sucesso podem, às vezes, ser incertas, mas elas nos permitirão retirar lições para nosso próprio contexto. Isso parece ser a segunda lição: os contextos são tão distintos, e nossos sistemas políticos e administrativos diferem tanto (é provável que nossas administrações sejam muito mais distintas do que nossas empresas privadas, principalmente em um mundo "globalizado") que qualquer lição muito simples será falsa, porque todas as relações causais estarão "superdeterminadas". Portanto, deveríamos suspeitar de qualquer modelo genérico que traga conselhos com receitas aparentemente fáceis sobre bons governos e boa governança. Mas, mesmo assim, se nos dermos conta de que os contextos são diferentes e que os resultados dependem de uma série de variáveis e influências, poderemos tirar lições válidas de outras experiências.

Algumas conclusões sobre as diferentes estratégias de implementação e políticas administrativas dos nossos "países reformistas" podem ser usadas como um exemplo final: em quase todos os casos as reformas parecem ser mais bem-sucedidas se forem coordenadas e implementadas por atores centrais relevantes, isto é, em geral pelos ministérios da área financeira ou, ainda melhor, pelo governo central. Uma estratégia clara de reforma e comunicação, que demonstre aos participantes e observadores que a modernização administrativa é prioritária na agenda política e que atores políticos relevantes se importam com ela, parece ser de grande ajuda. Mas isso obviamente não vale para todos os países (os Países Baixos parecem ser uma exceção), e nem é, por motivos óbvios, uma estratégia facilmente transferível para a Alemanha, com seu sistema político-administrativo altamente fragmentado, legalista e voltado para o consenso. Mesmo assim, se tentamos desenhar uma estratégia de implementação viável, observar outras experiências pode ser útil.

Outra lição diz respeito à disponibilidade de avaliações. Uma das conclusões do nosso estudo comparativo é a distribuição desigual de 
avaliações disponíveis a respeito dos processos de modernização em curso.

De modo bastante grosseiro, há uma divisão norte-sul. Na Escandinávia existem várias (ainda insuficientes, e nem sempre "estado da arte") avaliações sistemáticas das reformas governamentais. Algumas dessas foram feitas por agências do governo, geralmente por ministérios de finanças ou departamentos de auditoria; mas existem também avaliações "independentes" feitas por cientistas e organizações de pesquisa. Alguns desses estudos, também de fontes oficiais, utilizam um "verdadeiro" desenho de pesquisa comparativa, tentando comparar, por exemplo, agências regidas por contratos com as tradicionais, ou perseguindo análises sistemáticas de desempenho e produtividade do tipo "antes e depois". É claro que muitas “culturas” de modernização diferentes (mais empíricas/ incrementais na Escandinávia, mais prescritivas/racionalistas nos países Anglo-Saxões) também são encontradas na maneira como as avaliações são solicitadas e utilizadas.

Por último, uma palavra sobre o desenho desta pesquisa, em que especialistas nacionais puderam realizar sua própria análise subjetiva de conceitos, estratégias e resultados, com base em uma estrutura e em questionário comuns, e discutiram a fundo uns com os outros. Se concordarmos que os contextos são de grande importância, que os efeitos são difíceis de se medir, e que os pressupostos causais são pouco confiáveis, esta parece, ao menos na nossa opinião, uma forma bastante apropriada e confiável de conduzir um projeto de pesquisa comparativa. No final, não podemos apresentar resultados quantitativos e testados. Tanto a análise das experiências nacionais e dos sucessos quanto a avaliação geral dos resultados comparativos, relevantes para muitos, senão todos os países da nossa amostra, baseiam-se fortemente no conhecimento, experiência e julgamento de cada um dos pesquisadores. Mas isso, ao menos para propósitos práticos, está relacionado com o "conhecimento utilizável” e orientação política - conforme se pretendia no desenho da pesquisa - e é preferível a qualquer tipo de exatidão pseudocientífica. No final, todas as conclusões viáveis desse tipo de esforço de pesquisa dependem dos pesquisadores, os quais são capazes de formulá-las. Se Frieder Naschold ainda estivesse conosco no final desse projeto de pesquisa, temos certeza de que nossas conclusões teriam sido de alguma forma distintas e, possivelmente mais audaciosas. 
* In memoriam Frieder Naschold 1940-1999, Universidade de Postdam, Alemanha. A idéia original do projeto foi desenvolvida por Frieder Naschold, diretor do Centro de Ciências Sociais de Berlim, cuja trágica morte em 1999 é a principal razão pela qual o relatório final e a publicação com as conclusões não estarem concluídos. O título completo do projeto original é "Reforma no Governo Central - Experiências e Melhores Práticas Internacionais para a Futura Modernização do Estado e da Administração na Alemanha". Foi apresentado na conferência organizada por Hellmutt Wolman, "Avaliando a nova gestão pública no mundo”, Rio de Janeiro, 13 e 14 de setembro, 2001. Publicação autorizada pelos autores.

\section{Referências bibliográficas}

DöHler, Marian; Verner, Jann. (2001), Relatório de País - Alemanha. Preparado para a conferência da PUMA/OCDE sobre Governança das Agências e Autoridades Estatais. Paris, 19-20 de abril.

JANN, Werner; Wewer, Göttrik. (1998), “Helmut Kohl und der 'schlanke Staat': Eine

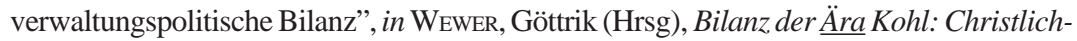
liberale Politik in Deutschland 1982-1998. Opladen: Leske + Budrich.

JANN, Werner. (1997), "Public Management Reform in Germany: A Revolution Without a Theory?”, in KICKERT, W.J.M. (ed), Public Management and Administrative Reform in Western Europe. Cheltenham: Elgar, p. 59-80.

KöNIG, Klaus; Füchtner, Natascha. (2000), "Schlanker Staat" - eine Agenda der Verwaltungsmodernisierung im Bund. Baden-Baden: Nomos.

Lindblom, Charles E., CohEn, David K. (1979), Usable Knowkledge. Social Sciences and Social problem Solving. Nova York, New Haven u.a: Yale University Press.

NASCHOLD, Frieder; JANN, Werner; ReICHARD, Christoph. (1999), Innovation, Effektivität, Nachhaltigkeit. Internationale Erfahrungen zentralstaatlicher Verwaltungsreform. Berlim: Sigma.

Pollitt, Christopher; Bouckaert, Geert. (2000), Public Management Reform. A Comparative Analysis. Oxford: Oxford University Press.

ReICHARD, Christoph. (1997), "Neues Steuerungsmodell: Local Reform in Germany", in KICKERT, Walter J.M. (Hhsg.), Public Management and Administrative Reform in Western Europe. Cheltenham: Elgar, p. 59. 


\section{Melhores práticas na modernização do Estado \\ Werner Jann e Christoph Reichard}

Este artigo resume os primeiros resultados de um projeto de pesquisa internacional comparativa que avalia as mais importantes realizações da modernização dos Estados centrais em diferentes "países reformistas" ocidentais. Baseado em relatórios dos países por um número de conhecidos especialistas em administração pública e gestão pública da Dinamarca, Países Baixos, Nova Zelândia, Suécia, Suíça, Reino Unido e Estados Unidos, novas práticas, que evoluíram de maneira similar em diferentes países, com tradições administrativas obviamente muito diferentes, culturas e caminhos de reforma, e que parecem funcionar, são identificados e analisados. A principal ênfase é na implementação, nos processos e nas práticas reais e no impacto de inovações em áreas claramente definidas de políticas públicas e/ou projetos, e não nos programas e estratégias gerais de modernização. O texto concentrase em três descobertas principais: em uma nova lógica de direção no nível do governo central (agencificação e direção contratual), nas inovações no campo do pessoal (normalização e orientação para a performance nos sistemas de pessoal) e na gestão financeira (orçamento e controle). O estudo conclui com algumas observações sobre estratégias de implementação (política administrativa) e com algumas experiências gerais deste tipo de esforço internacional cooperativo de pesquisa bastante incomum, baseado mais no material disponível e no julgamento esclarecido que em um avançado desenho de pesquisa.

\section{La mejor práctica en la modernización del Estado \\ Werner Jann y Christoph Reichard}

Este artículo resume los primeros resultados de un proyecto de encuesta internacional comparativa que evalúa las más importantes realizaciones de la modernización de los estados centrales en diferentes "países reformistas" occidentales. Basado en informes para cada país hechos por un número de conocidos especialistas em Administración púbica y gestión pública de la Dinamarca, Países Bajos, Nueva Zelandia, Suécia, Suíza, Reino Unido y Estados Unidos, nuevas práticas, que evoluíran de manera similar en diferentes países, con tradiciones administrativas obviamente muy diferentes, culturas y caminos de reforma, y que parecem funcionar, son identificados y analisados. El principal énfasis es puesta en la implementación, en los procesos y prácticas reales y en el impacto de inovaciones en las áreas claramente definidas de políticas públicas y/o proyectos, pero no en los programas y estratégias generales de modernización. El texto concentra su foco en tres descobertas principales: en una nueva lógica de direción en el nivel del gobierno central (agencificación y dirección contratual), en las inovaciones en el campo del personal (normalización y orientación para la performance en los sistemas de personal) y en la gestión financiaria (presupuesto y control). El estudio concluye con algunas observaciones sobre las estratégias de implementación (política administrativa) y con algunas experiencias generales deste tipo de un esfuerzo internacional cooperativo de encuesta bastante inusual, basado más en el material disponible y en el juício esclarecido que en un avanzado dibujo de encuesta.

\section{Best practice in central government modernization Werner Jann and Christoph Reichard}

This paper summarizes first findings from an international comparative research project evaluating major achievements of central state modernization in different western "reformcountries". Based on country reports by a number of well-known public administration
Revista do

Serviço

Público

Ano 53

Número 3

Jul-Set 2002

Werner Jann é presidente do

European

Group of Public Administration

(EGPA) e

professor de

ciência política,

administração e

organização na

Universidade de

Potsdam,

Alemanha.

Christoph

Reichard é $\mathrm{PhD}$

em Economia e

Administração

Pública pela

Universidade de

Freiburg e

professor de

Gestão Pública

na Universidade

de Potsdam,

Alemanha.

Contatos:

jann@

rz.uni-potsdam.de

puma@

rz.uni-potsdam.de 
and management experts from Denmark, the Netherlands, New Zealand, Sweden, Switzerland, United Kingdom, and the United States, new practices, which have evolved similarly in different countries, with obviously quite different administrative traditions, cultures and reform paths, and which seem to work, are identified and analysed. The main emphasis is laid on the implementation, on the real practices and processes and on the impact of innovations in clearly defined policy areas and/or projects, and not on general modernization strategies and programmes. The paper concentrates on three main findings: on a new logic of steering at central government level (agencification and contract steering), on innovations in the field of personnel (normalisation and performance orientation of personnel systems) and on public financial management (budgeting and accounting). It concludes with some observations about implementation strategies (administrative policy) and with some general experiences from this kind of a rather unusual international cooperative research effort, based more on available material and informed judgement than on an advanced research design. 